\title{
Ideologías lingüísticas en las obras misionero-coloniales sobre el mapudungun (Valdivia, Febres y Havestadt)*
}

\author{
Linguistic ideologies in the missionary-colonial works on \\ Mapudungun language (Valdivia, Febres and Havestadt)
}

Nataly Cancino Cabello**

\section{RESUMEN}

Estudiamos las ideologías lingüísticas en las obras misionero-coloniales referidas al mapudungun: Arte (Luis de Valdivia, 1606), Arte (Andrés Febres, 1765) y Chilidúgú (Bernardo de Havestadt, 1777). Para ello, establecemos relaciones teóricas entre ideologías lingüísticas y lingüística misionera, y definimos un estudio interpretativo. En el análisis nos centramos en la concepción del mapudungun como lengua general y en la universalidad-particularidad del lenguaje. A partir de esto, corroboramos la presencia de ideologías lingüísticas en el conjunto, lo cual justifica su empleo como corpus.

\begin{abstract}
We study the linguistic ideologies in the missionary-colonial works on Mapudungun language: Arte (Luis de Valdivia, 1606), Arte (Andrés Febres, 1765), and Chilidúgú (Bernardo de Havestadt, 1777). To do this, we establish theoretical relationships between linguistic ideologies and missionary linguistics, and we define an interpretive study. In the analysis, we focus on Mapudungun's notion as a general language and the universality-particularity of language. With this work, we corroborate the presence of linguistic ideologies in the set, which justifies that we use as a corpus.
\end{abstract}

Palabras clave:

lingüística

misionera,

ideologías

lingüísticas,

mapudungun.
Keywords:
Missionary
linguistics,
Linguistic
ideologies,
Mapudungun
language

\footnotetext{
* $\quad$ Este artículo se inscribe en el proyecto Fondecyt de Iniciación 11170578, "Gramáticas misioneras de Chile colonial". Una versión preliminar se presentó en el II Coloquio de Lingüística Histórica, Pontificia Universidad Católica de Chile, Santiago, 15 y 16 de noviembre de 2018.

** Chilena. Doctora en Lingüística por la Universidad de Sevilla. Investigadora Universidad de Playa Ancha, Valparaíso, Chile. nataly.cancino.cabello@gmail.com.
} 


\section{Presentación}

Los estudios formales acerca del mapudungun encuentran sus primeros antecedentes en el trabajo lingüístico que llevaron a cabo misioneros católicos en la Capitanía de Chile durante la época colonial. La labor de estos religiosos se enmarca en un contexto americano más amplio de producción de este tipo de obras. En efecto, la discusión respecto de la lengua o las lenguas que se emplearían para la evangelización de los nativos fue objeto de discusión entre las autoridades coloniales. No obstante, debido a necesidades prácticas - como la insuficiencia del número de misioneros para enseñar el español一, y pese a las objeciones ideológicas - como las dudas en cuanto a la capacidad de aprendizaje de los indígenas- esta labor se realizó mayoritariamente en lenguas vernáculas (Martínez, 1997), aunque hubo fluctuación entre el uso de las lenguas generales y de otras locales.

Para promover la enseñanza y el aprendizaje de los idiomas vernáculos, los misioneros recurrieron a la experiencia europea previa en el ámbito lingüístico y, en consecuencia, crearon manuales gramaticales y/o lexicográficos en los que describían la lengua que pretendían enseñar (Zimmermann, 2006). Por este motivo, legaron un amplio conjunto de obras que ha servido como fuente para los estudios de la lingüística misionera moderna, iniciada a finales del siglo XX.

En este artículo nos centramos en un corpus local de la lingüística misionero-colonial, esto es, en tres obras conocidas sobre el mapudungun: Arte de Luis de Valdivia, de 1606; Arte de Andres Febres, de 1765; Chilidúgú de Bernardo de Havestadt, de 1777. En ellas, nos proponemos determinar si se configura un cuerpo ideológico uniforme en torno a las lenguas, especialmente respecto de la lengua mapuche. Adicionalmente, buscamos corroborar el valor de estas obras como corpus de análisis desde la perspectiva de las ideologías lingüísticas.

Con los fines expuestos, en primer lugar, planteamos los alcances y las relaciones entre lingüística misionera e ideologías lingüísticas. En segundo lugar, nos referimos a la producción misionera en torno al mapudungun en la época colonial y repasamos, en consecuencia, el contexto y la estructura de las tres obras misionero-coloniales del mapudungun. Para analizar dichas obras, definimos que nuestro estudio es de índole interpretativo en un paradigma cualitativo, posee carác- 
ter comparativo y toma como base los paratextos de las obras. En el apartado dedicado al análisis, informamos acerca de la expresión y el tratamiento de las ideologías lingüísticas en el corpus y nos centramos en la delimitación del mapudungun como lengua general y en la relación universalidad-particularidad del lenguaje. Por último, ofrecemos las conclusiones de la investigación, las cuales corroboran la presencia de ideologías lingüísticas en las obras, lo cual justifica su delimitación como conjunto.

Cabe mencionar que este trabajo forma parte de un proyecto de investigación mayor. Los recursos descriptivos en las obras misionerocoloniales del mapudungun se han estudiado en Cancino (2020), en referencia a la categoría gramatical nombre. El manuscrito que aquí presentamos ha de entenderse como complementario de aquel.

\section{Ideologías lingüísticas y lingüística misionero- colonial}

Para presentar los conceptos teóricos que sustentan nuestro trabajo, nos preguntamos por las posibilidades teóricas y metodológicas de aunar dos nociones: lingüística misionera e ideologías lingüísticas. La relación entre estos dos conceptos está presente en trabajos previos relativos a obras misioneras del ámbito de colonización hispana. Uno de los precursores es Miguel Ángel Esparza (2003; 2015; 2016; 2017; 2019), quien se ha centrado en lenguas de la zona mesoamericana y andina; el autor, sin presentar una discusión teórica acerca de estos conceptos, describe el "ideario" que sustenta en trabajo de los misioneros y sus líneas de continuidad. Respecto del mapudungun, hallamos el ensayo de Olate Vinet, Cisternas, Wittig y Flores (2017), en el cual se estudian las ideologías lingüísticas de los capuchinos bávaros que misionaron en el sur de Chile a partir de mediados del siglo XIX; además de hacer un repaso por asuntos teóricos, este trabajo aporta un estado de la cuestión en cuanto a los estudios de ideologías y actitudes lingüísticas hacia el mapudungun, considerando la época actual.

En las últimas décadas, "los estudios de ideologías lingüísticas han mostrado ser una fuente rica en recursos conceptuales y metodológicos para aproximarse a la relación entre lenguaje y cultura" (Rojas, 2013, p. 87). A juicio de Garrett (2010), el concepto de ideología lingüística ha resultado útil en tareas vinculadas con la variación y cambio 
lingüístico y con la política lingüística; su éxito se debe a que se ocupa de la valoración de las lenguas y de los trasfondos políticos de esta. Según Cisternas (2017), ha sido justamente lo fructífero de este concepto lo que ha llevado a varios autores a plantear una definición del mismo, lo que dificulta su conceptualización: "se puede encontrar una multiplicidad de definiciones del concepto, las cuales suelen ser bastante genéricas, además de divergir en algunos puntos" (p. 102).

Con el fin de delimitar el concepto de ideologías lingüísticas, Cisternas (2017) repasa el tratamiento que varios autores hacen de este término: Silverstein (1979), Irvine (1989), Rumsey (1990), Woolard (1998), Kroskrity (2004) y Spolsky (2004). El investigador sistematiza estas propuestas y concluye que contienen las siguientes ideas base: las ideologías lingüísticas

(a) son un conjunto de ideas o creencias[,] (b) se refieren a las lenguas y su uso social[,] (c) tienen un carácter implícito o explícito[,] (d) conforman un sistema o conjunto interrelacionado[,] (e) su contenido se ve influido por el contexto en el que se sitúa el sujeto (Cisternas, 2017, p. 104).

A partir de lo anterior, propone que

las ideologías lingüísticas son un sistema de ideas sobre una lengua, y el papel que esta desempeña y debiese desempeñar en la sociedad, que emerge en un contexto sociopolítico y sociocultural determinado, y se ve influido - aunque no determinado- por la posición que ocupa el sujeto en el espacio social (Cisternas, 2017, p. 105).

Tomando como centro esta idea, nos interesa profundizar en los postulados de Kroskrity (2010) - considerado uno de los autores más influyente sobre este tema-, quien distingue cuatro "capas" de significación en las ideologías lingüísticas. En primer lugar, indica que estas representan la percepción del lenguaje y el discurso de un grupo social o cultural específico; por lo tanto, las nociones de un miembro se basan en la experiencia social y, a menudo, se vinculan con sus intereses; de ese modo, se intenta emplear el lenguaje como un lugar para promover, proteger y legitimar esos intereses. Con esta posición se refuta la idea de que existe un hablante desinteresado sociopolíticamente. Aunque los intereses se hacen más evidentes 
cuando se trata de grupos contendientes o culturales aparentemente homogéneos, es central en la propuesta de Kroskrity (2010) el hecho de que las prácticas culturales no son estrictamente dicotómicas, sino más bien graduales, parciales y fragmentarias. En segundo lugar, propone que las ideologías lingüísticas son múltiples debido a las muchas divisiones sociales significativas en los grupos socioculturales, como clase, género, élites y generaciones, entre otras. Como consecuencia de ello, las ideologías lingüísticas se basan en una experiencia social que no se distribuye uniformemente. En tercer lugar, los miembros de un grupo pueden tener diversos grados de conocimiento de las ideologías lingüísticas, de modo que estas pueden ser explícitas (en especial en espacios o rituales determinados) y pueden, asimismo, estar implícitas en el uso. En cuarto lugar, Kroskrity (2010) indica que las ideologías lingüísticas tienen un papel mediador entre las estructuras sociales y las formas de habla, de modo que unen las experiencias socioculturales de los hablantes con sus recursos lingüísticos y discursivos, ya que estos quedan indexados a dicha experiencia sociocultural.

Otros autores aportan conceptos que resultarán útiles para nuestro trabajo, puesto que permiten las ideologías lingüísticas; estos son la indicialidad y las representaciones sociolingüísticas. Respecto del primer término, del Valle y Meirinho-Guede (2015 remitiendo a Hanks, 2000) proponen que la indicialidad "hace que el valor de un enunciado (...) esté (...) en su capacidad para señalar elementos del contexto de la enunciación, indicar identidades sociales y construir relaciones entre los interlocutores" (p. 625). Sostienen que el lenguaje implica la negociación de identidades y relaciones sociales, y no solo el uso de una lengua.

Las representaciones sociolingüísticas, en tanto, están facilitadas por el contexto. Narvaja y del Valle (2010) indican que estas pueden manifestarse a través de formas discursivas pertenecientes a varios ámbitos, entre los que se cuentan los textos en los que se sanciona el uso del lenguaje desde frentes políticos y jurídicos, textos normativos (diccionarios, gramáticas) y textos temáticos (artículos de opinión); además, identifican estas representaciones en la asociación de formas de habla con determinados grupos de personas, ya sea a través de la imitación o en la praxis discursiva real (estereotipos sociolingüísticos). 
Por otra parte, el segundo de los términos en revisión en este apartado, la lingüística misionera, se emplea para referirse a dos conceptos distintos pero relacionados: por una parte, designa el corpus de obras escritas por religiosos para promover la evangelización; y por otra, se refiere a la disciplina que tiene a estos textos como objeto de estudio, la cual forma parte de las investigaciones de la historiografía lingüística, en cuanto esta se ocupa "[d]el conjunto cronológico y geográfico de los acontecimientos, los hechos, los procesos de conceptualización y de descripción, y los productos que han moldeado tradiciones de pensamiento y de quehacer lingüísticos" (Swiggers, 2009, p. 68-69). En ese sentido, le compete a la disciplina lingüística misionera el estudio acerca de la reflexión en torno a las lenguas y la interpretación de los acontecimientos que la afectan. La importancia de este asunto es tan relevante que Esparza (2017) plantea que "Si, a partir del estudio de las obras de los misioneros, se desprende claramente que existe un cuerpo doctrinal presentado en forma de ideario lingüístico (...) que ha ejercido una influencia comprobable, podremos hablar propiamente de lingüística misionera" (p. 136).

En esta línea, Oesterreicher (2019) sostiene que los estudios de la lingüística misionera deben "radicalizar la interpretación del momento histórico" (p. 412). Para ello, propone tres vías: analizar los textos sincrónica y diacrónicamente; ponderar prácticas sociales y el saber lingüístico, lo cual "implica la identificación de supuestos teóricos, de estrategias y preceptos descriptivos y de ejemplos transmitidos a veces de un texto a otro" (p. 412); e identificar la recepción y difusión de las obras. En el segundo punto señalado por el investigador, se ligan las ideologías lingüísticas y la lingüística misionera.

Creemos, además, que esta relación se inserta en una concepción de la ciencia lingüística que vincula la lengua y lo sociocultural. De hecho, Olate et al. (2017) justifican su trabajo acerca de los capuchinos bávaros en Chile con una afirmación que va en este sentido:

La indagación de las ideologías lingüísticas de actores importantes durante el proceso de construcción de la sociedad nacional y regional es una tarea necesaria que permite comprender la trayectoria de las creencias y actitudes acuñadas en el seno de la sociedad regional y chilena actual. El arraigo y la consolidación de comportamientos y valoraciones sociolingüísticas y culturales acerca de 
la diferencia y homogeneidad se nutren de la historicidad de los imaginarios promovidos por estos agentes relevantes, quienes impactan en el pensamiento de una época, posibilitando la génesis o consolidación de ideologías lingüísticas que alimentan los imaginarios y las representaciones de una sociedad a lo largo del tiempo, incluso hasta la actualidad (p. 137).

\section{Lingüística misionero-colonial en torno al mapudungun}

Aunque no se sabe exactamente cuántas obras de mapudungun pueden haber circulado en Chile durante la época colonial, hasta nuestros días han llegado tres de ellas: Arte y gramatica general de la lengua que corre en todo el Reyno de Chile de Luis de Valdivia, impreso en Lima (Perú), en 1606; Arte de la lengua general del Reyno de Chile de Andrés Febres, impreso en Lima, en 1765; Chilidúgú de Bernardo de Havestadt, impreso en Westfalia (Alemania), en 1777.

Los autores de estas tres obras nacieron en Europa: Luis de Valdivia (1560?-1642) era oriundo de Granada, España; Andrés Febres (1734-1790) provenía de Manresa, Cataluña; Bernardo de Havestadt (1714-1781) era de Colonia, Alemania. Los tres produjeron sus tratados, no obstante, en el marco de la evangelización de los mapuches en la zona centro-sur de Chile, por lo que sus obras surgen a partir de la realidad misional y como producto del contacto con los naturales. Los tres autores también tienen en común el hecho de ser jesuitas, de modo que su preocupación por las lenguas vernáculas se explica por principios ignacianos: el ideal misionero y el interés por la acomodación a la capacidad de los nuevos receptores (Rosa, 1997). Además, la Compañía de Jesús tenía un modelo formativo unitario y había descrito las lenguas indígenas en la zona andina (quechua y aymara, por ejemplo).

Ahora bien, pese al origen misionero de los tratados y a la filiación religiosa común de los autores, el contexto ideológico, social y político de producción de las tres obras es bastante diferente. Aunque este hecho puede resultar evidente si se consideran sus fechas de edición, las formas de creación y los circuitos comunicativos particulares, repasaremos los trazos generales de las condiciones de elaboración de estas obras misionero-coloniales. 
Valdivia (1606) indica en la dedicatoria de su Arte que escribió el texto a fines del siglo XVI, mientras misionaba entre los mapuches del sur. La obra se imprimió en 1606, durante una estancia del jesuita en Lima, y tenía como finalidad apoyar la implementación de la guerra defensiva, cuya estrategia consistía en promover el diálogo con los indígenas y en no emplear las armas hispanas, salvo en caso de ataque; a cambio, los naturales permitirían que los misioneros entraran a evangelizar a sus territorios.

El Arte de Febres (1765) se creó también en Chile, aunque se imprimió en Lima, debido a que en el territorio chileno no había imprenta. Esta obra se elabora cuando el alzamiento mapuche de 1755 era determinante en las relaciones con los hispanos; mientras que el rol de la Compañía de Jesús era cuestionado y su actuación en Chile se veía afectada por la discusión acerca de las misiones paraguayas (Araya y Martínez, 2017). Para el momento de la expulsión, que se produjo en 1767, el Arte de Febres (1765) ya se encontraba publicado y la censura antijesuítica parece no haber incidido en su empleo.

Por último, Chilidugú de Havestadt (1777) se publicó en Alemania, diez años después de la expulsión de la Compañía de Jesús de los territorios hispanos. En esa situación, Bernardo de Havestadt tuvo la intención de divulgar entre los jesuitas sus conocimientos acerca de la lengua y la cultura de los mapuches, así como sus experiencias con los indígenas y materiales elaborados por otros autores y adaptados por él. La estructura de los tres tratados se expresa en las siguientes tablas:

Tabla 1.

Componentes del Arte (1606) de Valdivia.

\begin{tabular}{lll}
\hline & $\begin{array}{l}\text { Privilegio } \\
\text { Licencia } \\
\text { Aprobaciones } \\
\text { Dedicatoria } \\
\text { Proemio }\end{array}$ & Paratextos \\
Tratado mapuche & $\begin{array}{l}\text { Doctrina } \\
\text { Catecismo } \\
\text { Confesionario }\end{array}$ & Textos religiosos \\
\cline { 2 - 2 } & $\begin{array}{l}\text { Arte } \\
\text { Vocabulario }\end{array}$ & Textos lingüísticos \\
\hline
\end{tabular}

Fuente: Elaboración propia. 
Tabla 2.

Componentes de Arte (1765) de Febres.

\begin{tabular}{|c|c|c|}
\hline & $\begin{array}{l}\text { Dedicatoria } \\
\text { Aprobación } \\
\text { Licencias } \\
\text { Censuras } \\
\text { Erratas } \\
\text { Prólogo-Índice }\end{array}$ & Paratextos \\
\hline \multirow{4}{*}{$\begin{array}{l}\text { Tratado } \\
\text { mapuche }\end{array}$} & $\begin{array}{l}\text { Arte } \\
\text { Vocabulario hispano-chileno }\end{array}$ & \multirow[t]{2}{*}{ Textos lingüísticos } \\
\hline & Calepino & \\
\hline & $\begin{array}{l}\text { Doctrina cristiana (con: oraciones, } \\
\text { catecismo, rosario, confesionario, } \\
\text { sacramentos, pláticas) }\end{array}$ & Textos religiosos \\
\hline & Coplas & Otros \\
\hline
\end{tabular}

Fuente: Elaboración propia.

Tabla 3.

Componentes de Chilidúgú (1777) de Havestadt.

\begin{tabular}{|c|c|c|}
\hline & $\begin{array}{l}\text { Licencias } \\
\text { Índice } \\
\text { Dedicatoria }\end{array}$ & Paratextos \\
\hline \multirow{3}{*}{$\begin{array}{l}\text { Tratado } \\
\text { mapuche }\end{array}$} & $\begin{array}{l}\text { Gramática } \\
\text { Vocabulario mapuche } \\
\text { Índice de voces latinas }\end{array}$ & Textos lingüísticos \\
\hline & Catecismo & Textos religiosos \\
\hline & $\begin{array}{l}\text { Descripción de las partes del mundo, } \\
\text { ser humano y ciudad; partituras } \\
\text { musicales; diario de viaje; poema latino } \\
\text { (apéndice) }\end{array}$ & Otros \\
\hline
\end{tabular}

Fuente: Elaboración propia.

Como se aprecia, del mismo modo en que suele ocurrir en gran parte de las obras de la lingüística misionero-colonial, los tratados que analizamos son misceláneos, pues están formados por clases textuales diferentes en sus fines y estructuras. En primer lugar, se distingue un aparato paratextual, inserto como consecuencia del proceso de control civil y eclesiástico en la producción de las obras y en cuyos rasgos nos detendremos en la siguiente sección. Por otra parte, hallamos textos que describen la lengua mapuche, entre los cuales destacan aquellos 
de contenido gramatical (gramáticas y artes), y de carácter lexicográfico (vocabularios y calepino). Debido a que el motivo del aprendizaje de los idiomas nativos era la evangelización de los naturales, se incluyeron escritos religiosos. Entre estos, están los discursos instruccionales, como doctrinas y catecismos, destinados a la formación de los indígenas en los asuntos de la fe; también se hallan textos para la administración de los sacramentos, como obras para bautismo, confesión, matrimonio, extremaunción; y los textos homiléticos, como las pláticas. Además, escritos de diverso tipo ("otros") complementaban las obras, lo que ilustra el valor histórico y etnográfico de estas.

\section{Aspectos metodológicos}

Pretendemos, como objetivo general, determinar si se configura un cuerpo ideológico uniforme en torno a las lenguas, especialmente respecto de la lengua mapuche, en las tres obras misionero-coloniales de mapudungun: Valdivia (1606), Febres (1765) y Havestadt (1777). Con ello, adicionalmente, buscamos delimitar si estas tres obras independientes pueden considerarse como un conjunto. Como supuesto de investigación sostenemos que, pese a las exigencias de cada contexto de producción, existe un cuerpo ideológico que sustenta la descripción del mapudungun en las tres obras misionerocoloniales. Por lo anterior, y también a modo de supuesto, validamos su empleo como corpus.

Para lograr nuestros objetivos hemos tomado las decisiones metodológicas que se desarrollan a continuación. Primero, empleamos una metodología interpretativa en un paradigma cualitativo, lo que nos sitúa en la línea de Olate et al. (2017). Ello, porque analizamos los presupuestos epistemológicos que subyacen tras el quehacer investigativo; este estudio, en consecuencia, se enmarca en la vertiente social del lenguaje e intenta comprender el contexto de la producción de la lingüística, tanto del momento histórico como de los autores. Se trata, por lo tanto, de una investigación de carácter interdisciplinario.

En segunda instancia, analizamos las obras desde una perspectiva comparativa, pues consideramos que el análisis de las ideas en torno a las lenguas y el lenguaje se debe realizar "a partir de la constatación de relaciones entre textos, pues son las relaciones entre ellos las que nos permitirán, no ya solo establecer, sino interpretar, la 'influencia' de 
unos textos en otros, de unos autores en otros" (Esparza, 2003, p. 70). En esta decisión, también seguimos a Olate et al. (2017).

En tercer lugar, abordamos los paratextos de las obras misioneras, en consonancia con Esparza (2017; 2019), Calhoun (2017), Olate et al. (2017) y Cancino (2017a y 2018). El interés en los liminares se debe a que ellos informan aspectos disciplinarios, métodos e idearios en torno a las lenguas (Esparza, 2015) y exponen políticas y líneas de acción del lenguaje (Cancino, 2017a).

Por otra parte, una tipología de los preliminares en las obras misioneras que resulta operativa en este trabajo se encuentra en Cancino (2017a). En aquel artículo se propone una clasificación de los paratextos entre aquellos de carácter legal y los de la tradición escritural. Los liminares legales se insertan porque los contenidos de las obras, antes de la impresión, pasaban por un proceso de control aplicado a todos los volúmenes que circulaban por los territorios españoles. Dicha censura, de carácter civil y eclesiástico, regulaba aspectos morales y concernientes al dominio de la lengua, y se manifestaba mediante textos obligatorios que dejaron huella en el proceso de edición y control de la impresión: pareceres y aprobaciones, licencias y autorizaciones. Algunos de estos documentos también regulaban el aspecto comercial y económico de la obra, como tasas (precio) y privilegios (beneficiarios, duración, territorio). En tanto, los paratextos de la tradición escritural se incorporan por influencia europea y, entre ellos, encontramos dedicatorias y prólogos o proemios; en ellos se manifiesta "la posición de los autores ante la obra y ante su entorno (ideológico, histórico, institucional)" (Cancino, 2017a, p. 423). Para Gómez Asencio (2002), en tanto, estos escritos son especialmente interesantes, ya que contienen asuntos que "(por las razones que sean) ha[n] merecido especial atención -y mención- de parte de sus autores" (p. 1202).

\section{Análisis de ideologías lingüísticas en el corpus}

En este apartado nos centraremos en dos expresiones en el corpus: la elección del mapudungun como lengua general y la relación universalidad-particularidad del lenguaje. En el primer punto abordaremos la implementación de una noción de uniformidad de la lengua (y su expresión variacional) y la política lingüística, mientras que en el segundo observaremos la relación comparativa establecida entre 
el idioma mapuche y las lenguas de tradición gramatical, en especial, el latín; del mismo modo, estudiaremos los elogios que aparecen en los textos.

\subsection{Mapudungun: lengua general}

Una de las primeras delimitaciones conceptuales e ideológicas acerca del mapudungun se explicita en la portada del Arte de Luis de Valdivia de 1606: Arte y gramatica de la lengva general que corre en todo el Reyno de Chile; ello constituye, también, una determinación política respecto de la lengua. Con lo anterior se informa, por una parte, que el texto contiene una gramática general del idioma mapuche $\mathrm{y}$, por otra, que el mapudungun es una lengua general. Estos aspectos pasarán de manera diferente a la obra de Febres (1765), mientras que no se informan en Havestadt (1777).

El carácter general de la lengua de Chile se explica en el apartado paratextual "Al lector" de Valdivia (1606, s/p.), donde se entiende por "general" una lengua hablada uniformemente entre la población prehispánica y aquella que le es contemporánea al autor. En el territorio chileno el mapudungun se habla desde Coquimbo hasta Chiloé y desde la cordillera al mar:

no ay mas de efta lengua [...] porque aunque en diuerfas prouincias deftos Indios ay algunos vocablos diferētes, pero no fon todos los nombres verbos y adverbios diuerfos, y afsi los preceptos y reglas defta Arte fon generales para todas las Prouincias (Valdivia, $1606, \mathrm{~s} / \mathrm{p}$.).

El asunto de la variación interna de las lenguas indígenas fue un tema respecto del que debieron decidir los misioneros al crear sus artes. En el mundo andino, Domingo de Santo Tomás (1560), primer codificador del quechua, optó por buscar una lengua vehicular generalizadora en su Arte o gramatica. En tanto, el Arte de 1586, conocida como "el anónimo" o como "Antonio Ricardo", por el nombre de su impresor, y recientemente adjudicada a Blas Valera, normaliza el quechua en su dialecto cuzqueño, "considerado el más prestigiado, arrinconando con ello a los demás dialectos quechuas y reorientando para la posteridad religiosa los hábitos lingüísticos de la capital imperial inca" (Calvo Pérez, 2013, p. 225). Ludovico Bertonio (1603/2015), por su parte, al describir el aymara en su Arte y gramática muy copiosa (1603), reconoce 
varios dialectos de esta lengua y, de ellos, opta por describir el lupaca, cuyos rasgos admira por razones que adjudica a la ubicación de los hablantes (en el centro del mundo aymara); ahora bien, también menciona que en Juli, núcleo jesuítico de la zona, los indígenas hablaban esta variedad, por lo cual resulta conveniente conocerla para la orden. En los casos del quechua y aymara vemos que, más allá de los fundamentos, la elección de un modelo de lengua para su uso y descripción era una práctica habitual y consolidada en la tradición misionera del área andina.

Ahora bien, aunque Valdivia (1606) reconoce la uniformidad de la lengua general, presenta el catecismo y la doctrina con dos traducciones. Estas corresponden a las variantes dialectales que él ha reconocido: la de Santiago y la de La Imperial. Dichas variantes coinciden en su ubicación geográfica con los dos Obispados existentes en Chile para 1606 , lo cual se interpreta como una muestra de la insuficiencia de "la noción de 'lengua general' para describir los usos lingüísticos" y "como una forma de imposición de la organización eclesial por sobre las realizaciones efectivas del idioma" (Cancino, 2017b, p. 387). Tras la fundación del Obispado de Santiago en 1561, la creación del Obispado de La Imperial, en 1563, tenía un fin geoestratégico, pues su ubicación coincidía con la fundación de nuevas ciudades y se ubicaba equidistante entre Concepción y Osorno para resolver la organización diocesana de las ciudades entre el sur y el norte del río Biobío (Moreno, 2009). En ese sentido, la decisión de Luis de Valdivia se fundó en un razonamiento administrativo previo.

Febres, en su Arte (1765), también describe el mapudungun como lengua general e instala un programa descriptivo que llevó a Alvar (1997) a señalar que el jesuita catalán se aleja de la especulación, en lo que él considera "un sabio principio": "el uso convertido en norma, conforme a lo que establece el grupo social al que cada individuo pertenece y que practicaron los muchos lenguaraces de lenguas indígenas" (pp. 65-66). Esta afirmación se funda en el hecho de que Febres (1765) señala que se basó en su propia experiencia en el contacto con los mapuches: "puedo afegurarle, que todas las reglas de efte Arte fon ciertas, feguras, y conformes à lo que al prefente fe ufa; y no pondrè otra cofa, que no haya oído, y ufado, o no fepa de cierto" (s/p.). Por otra parte, el autor reconoce los distintos ámbitos de uso del mapudungun y aplica 
sus nociones cuando, tras la gramática, incorpora dos textos: uno que ejemplifica el habla familiar mapuche ("Diálogo" o "Dugulun") y otro que representa el habla pública y de los parlamentos ("Coyaghtun"). De ese modo, la lengua general tiene expresiones sociolingüísticas.

El concepto de lengua "general" remite a una elección de la administración civil y eclesiástica hispana que sostuvo, desde una perspectiva política, que las lenguas indígenas "generales" eran las "oficiales" (pp. 252-253) de su zona (Bustamante, 2005). Esta jerarquía se basaba en la situación de contacto europeo, africano y americano, pero también en las formas de vinculación interlingüísticas prehispánicas. Ahora bien, este es uno de los campos menos explorados en la lingüística histórica, pero quizás también uno de los más fecundos. La ausencia de fuentes y de métodos adecuados al área americana llevó a que no podamos todavía saber aún con exactitud cuántas lenguas ni cuántas variedades se hablaron en el continente, ni - mucho menos-cuáles fueron las relaciones establecidas entre ellas.

Lo que sí sabemos es que al momento de la llegada de los primeros conquistadores españoles, estos reconocieron un sinnúmero de idiomas y prontamente se percataron de que algunos de ellos funcionaban como lenguas francas, es decir, como códigos comunicativos que se caracterizaban "por su uso común en un territorio y por tener un mayor número de hablantes" (Cancino, 2017b, p. 382). En consecuencia, la jerarquización interlingüística "privilegió el empleo, la enseñanza y la descripción de las llamadas 'lenguas generales"' (Cancino, 2017b, p. 382). Según Flores Farfán y Zwartjes (2018), náhuatl, maya, chibcha, quechua y guaraní, las lenguas "más grandes de las Américas(,) (..) fueron registradas y expandidas por los misioneros, gracias a lo cual tenemos para cada una de ellas más de una fuente" (p. 174).

Es esta determinación la que encontramos en Valdivia (1606) y en Febres (1765) cuando reconocen al mapudungun como lengua general. Con una decisión de este tipo, se garantizaba la circulación de la obra y el empleo de la lengua para la evangelización, ya que era la preferida para la comunicación con los indígenas (Ridruejo, 2007). Las concepciones de lengua general que hallamos en los autores, de alguna manera, resultan convenientes para sus intereses, ya fueran políticos (reales y eclesiales), o bien, para animar al aprendizaje de la lengua. 


\subsection{Universalidad y particularidad del lenguaje humano}

De acuerdo con el marco intelectual europeo, los misioneros en América - de forma consciente o inconscientemente-, aplicaron un modelo de descripción lingüística que consideraba cada idioma particular en relación con otros y con determinados universales del lenguaje. A nuestro juicio, esto se manifiesta de dos maneras en las gramáticas del corpus: por una parte, por el empleo de un modelo predeterminado para estudiar una lengua y, por otra parte, a través del elogio de estas. En ambos procedimientos se establece un paradigma comparativo.

El primer punto, relativo al uso de un modelo para la gramatización de las lenguas indígenas, ha sido más atendido por los estudios de la lingüística misionera, debido a la evidente preeminencia del modelo latino para la descripción de las lenguas no europeas. Autores como Zwartjes (1998), Zimmermann (2006) y Hernández (2013) han buscado una explicación a este hecho y algunas de sus propuestas se han sistematizado en Cancino (2020). Desde la perspectiva de la relación de universalidad y particularidad,

para el misionero el que el latín se conciba como discurso gramatical genérico y particular a la vez (...) es (...) el resultado de su modelo teórico con dos niveles: el lógico o racional más universal y el nivel del uso con los particularismos de las lenguas. Por motivos prácticos de enseñanza de lenguas, al misionero le conviene contrastar los particularismos del uso latino o del uso castellano con el de las lenguas indígenas, contraste de usos que le permitía desarrollar su labor evangélica con eficacia y traducir la Doctrina Cristiana a dichas lenguas con mayor efectividad. Ahora bien, por otro lado, la lengua latina, una lengua que cree más perfecta, más completa y que se acercaba más a las características de la lengua primordial, mantiene más rasgos de la racionalidad universal y, por tanto, hay que explicar aquellas a partir de estas (Breva-Claramonte, 2008, s/p.).

La función del latín es servir como referencia para la descripción de las lenguas vernáculas americanas, pues "En latín está esculpida lo que podríamos llamar la 'teoría general de la gramática' del momento, que es la que facilita el andamiaje descriptivo" (Esparza, 2016, p. 27). En las obras referidas al mapudungun, efectivamente, se "ajusta el fenó- 
meno estudiado (el mapudungun) a los parámetros gramaticales del latín, distorsionando lógicamente la estructura de la lengua indígena" (Viereck Salinas, 2017, p. 372).

Respecto del segundo punto, las tres gramáticas que estudiamos presentan elogios para la lengua mapuche, los cuales provenían de la tradición europea. La gramatización de las lenguas vulgares suponía elevarlas a las lenguas de cultura de Antigüedad, por lo que se hacía necesario pensar su estatus y, de algún modo, justificar su idoneidad para ser estudiadas. En otras palabras, se debía demostrar que podían "someterse a reglas" (Esparza, 2016, p. 20), como el latín y otras lenguas que ya contaban con el prestigio de ser descritas.

El elogio se explica en una tradición moderna que se sustenta en la distinción entre lenguas de mayor y menor dignidad:

En consonancia con las preeminencias mentales de la época, el criterio utilizado para dar jerarquía a la pirámide lingüística moderna hundía sus raíces en la tradición bíblica y, merced a él, la cúspide del honor lingüístico le fue concedida a las tres lenguas que, se decía, habrían sido utilizadas por Dios para revelar a los hombres las Sagradas Escrituras: el hebreo, el griego y el latín. Quedan estas convertidas, de este modo, en lenguas sagradas, mientras que el resto de las hablas son inferiores a aquellas tres. (...) aunque es preciso insistir en que, de estas, la única que gozó de un cultivo realmente universal fue el latín, quedando el griego y, aún más, el hebreo reducidos a los siempre exiguos círculos de la erudición (Bouza Álvarez, 2018, p. 25).

Humanistas y escritores solían dedicar elogios a la lengua española. Estos discursos, "forman un conjunto de estereotipos, limitados y repetidos en innumerables combinaciones, presentes también en textos italianos y franceses, dentro del movimiento de conciencia lingüística de 'Elogio y Defensa' de las lenguas vulgares frente al latín" (Muñoz, 1994, p. 451). En los elogios y defensas del español, es usual afirmar la necesidad de valorar la lengua por su creación divina, así como por las cualidades que le permiten ser gramaticalmente descrita, pues "El 'Arte' perfeccionará esas cualidades, según un 'cuidado' ('cura' en el léxico latino) para igualar a la lengua propia con cualquiera, antigua o moderna" (Muñoz, 1994, pp. 452-453). 
Este proceso de reflexión acerca del rol y el estatus de una lengua en la gramatización, que se desarrollaba en Europa, se habría dado de manera mucho más veloz en relación con los idiomas vernáculos hablados en América, debido a que las condiciones en que se produce la labor de los misioneros, a juicio de Esparza (2016), otorga una impresión de urgencia respecto de la valoración de las lenguas originarias.

Valdivia (1606) elogia la lengua mapuche en el apartado preliminar "Al lector". Para Ridruejo (2007), este texto constituye un elogio, pues en él el autor encomia la facilidad del mapudungun y anima a su aprendizaje, pero "Valdivia no se limita a enumerar elogios de forma tópica sobre la suavidad o la belleza de la lengua, sino que adelanta también algunos de los rasgos más técnicos que luego reiterará" (Ridruejo, 2007, pp. 53-54).

El "Prólogo al lector" de Febres (1765) también se pone al alero de la tradición, puesto que en él se promueve la lengua mapuche adjudicándole facilidad y simplicidad. A tal punto llegan estas características, sustentadas en la regularidad de verbos y reglas, que el autor señala que "qualquiera, con mediana capacidad, y aplicación, por sì folo, en quince dias, ò en veinte, ò a lo mas en un mes, puede imponerfe con perfeccion en toda la teorica, y efpeculativa del Arte" (Febres, 1765, s/p.). Ahora bien, advierte que esta sentencia es válida solo en la adquisición de conocimiento gramatical, puesto que la experiencia (propia y ajena) le ha enseñado la diferencia entre preceptiva y práctica; advierte, entonces, que el mapudungun presenta excepciones e irregularidades.

Ya sea por los rasgos técnicos de la lengua o por el explícito interés en el aprendizaje de la misma, en ambas gramáticas destacan los intereses pedagógicos de los autores, lo cual se vincula con la tradición descriptiva de lenguas que son gramatizadas para enseñarse. Este propósito pedagógico explica también el modelo contrastivo para acercarse al mapudungun, al igual que a las demás lenguas vernáculas americanas.

Por su parte, en el Chilidúgú de Havestadt (1777) se inserta un paratexto diferenciado del resto, cuya traducción al español es la siguiente:

La lengua chilena, por cierto, tiene muchísimas características preclaras, raras e inauditas: una única declinación y una única conjugación, ambas absolutamente fáciles y obvias; un género único, 
ningún sustantivo o verbo anómalo; nada de reglas, a no ser que sean universales y sin excepción; y siempre la misma palabra, habiendo cambiado pocas letras, eliminadas o añadidas, hace las veces de sustantivo, de verbo, de adjetivo y de adverbio; esta lengua, habiendo añadido o insertado varias y a menudo muchísimas partículas, forma todas y cada una de sus palabras de manera compuesta, y no es raro que forme un sentido íntegro y bien largo.

De aquí que la lengua chilena sea una lengua muy fácil; y, aunque de bárbaros, no solo no es bárbara, sino que mucho mejor que otras lenguas; al igual que los Andes a otras montañas, así esta lengua supera a otras, al punto que quien es experto en el idioma chileno desdeñe otras lenguas, casi como si las mirara desde una torre, muy debajo de sí, reconociendo clara y evidentemente cuánto de superfluo haya en ellas, cuántas cosas les falten, y etcétera, y con cuánta razón y mérito a cada uno, que no sea chileno, se le pueda reprochar.

Si tu lengua es buena, sin embargo, aquella lengua chilena es mejor, lengua que este breve libro enseña ${ }^{1}$ (Havestadt, 1777, s/p.).

Este paratexto, sin título, no puede catalogarse más que como un elogio de la lengua. Ahora bien, a diferencia de lo que han hecho Valdivia (1606) y Febres (1765), Havestadt (1777) no explicita funciones pedagógicas ni otorga caracteres técnicos en esta alabanza al idioma mapuche, sino que hace una descripción ornamental y afectiva en comparación con otras lenguas. Esto se explica porque el carácter de esta obra es muy diferente del que presentaban sus antecesoras, producidas para la misión mapuche. El Chilidúgú, en cambio, se escribe tras la expulsión para un público que se supone ajeno a la vida entre las parcialidades indígenas en Chile. Tal como lo indica el autor en la "Dedicatoria al nombre de la Santísima Virgen María”, este tratado (1777) es la versión en latín de un texto que había escrito antes en español:

Este tratado, ¡oh, Virgen DEÍpara'! escrito por mí en español, con la ayuda de DIOS, ya desde el año 1765 dediqué al santísimo y más divino nombre de JESÚS, tu hijo amadísimo. Este mismo [tratado],

Agradecemos a José Antonio Cancino Alfaro el apoyo en la traducción latín-español. Término que únicamente se predica de la Virgen María, compuesto por "Dios" y "parió". Literalmente, significa "aquella que dio a luz a Dios". 
por mí mismo, tu siervo y esclavo, con la misma propicia divinidad, ahora traducido al latín, ¿a quién mejor que a tu santo nombre, y después del nombre de JESÚS santísimo, destine, dedique, consagre? (Havestadt, 1777, s/p.).

Aunque no explica las razones por las que decide reescribir la obra en latín, consideramos que con ello da muestra de una alta conciencia lingüística y de una comprensión del circuito comunicativo, ya que tras la expulsión de la Compañía de Jesús de los territorios de la Corona española, las condiciones no eran óptimas para que la obra circulara y se distribuyera en la colonia chilena. El otrora misionero escribe, entonces, para un nuevo público: ya no se dirige a religiosos neófitos que deben aprender el mapudungun para evangelizar entre los mapuches, sino que su público está formado por jesuitas - muchos también expulsos- residentes en Europa o en otros destinos, donde han aceptado a la Compañía de Jesús; este nuevo público tiene al latín como lingua franca y su preocupación por el idioma y la cultura de los mapuches se debe a intereses ilustrados.

Por otra parte, esta conciencia lingüística se vincula con la dimensión política de la lingüística misionera, la que también encuentra su explicación en el contexto de producción. La identificación de la lengua española como la lengua de la Corona es el resultado de una política y de una planificación previas, promulgadas y promovidas por la oficialidad hispana y van desde la afirmación que relacionaba lengua e imperio, hasta los decretos borbónicos de castellanización de 1770 . En consecuencia, es esperable que Havestadt (1777) asuma esa identificación lengua española-Corona española y que busque, entonces, mecanismos para alejarse del causante de sus desgracias y de la suerte que ha corrido la Compañía de Jesús.

\section{Conclusiones}

A partir del análisis, creemos que en las gramáticas jesuíticas producidas en Chile durante la época colonial se explicita una relación ideológica uniforme y continua respecto de las lenguas y, en particular, acerca del mapudungun, pese a que cada uno de estos trabajos obedece a su propio contexto y a sus particulares circunstancias de elaboración. Llegamos a esta conclusión tras identificar y describir las ideológicas lingüísticas que perduran en esta producción: el mapudungun como len- 
gua general, la consideración del contraste como método de enseñanza y aprendizaje de una lengua, la condición de alabanza como factor de promoción, la relación entre la lengua y la política, el análisis sociolingüístico y glotopolítico de las lenguas originarias. También consideramos que esta red de relaciones temáticas obedece a la continuidad de la tradición europea y a determinaciones generales de los misioneros y de otros agentes coloniales ante las lenguas de América.

Por lo anterior, validamos la configuración de un conjunto misionero-colonial sobre el mapudungun, formado por Arte de Valdivia (1606), Arte de Febres (1765) y Chilidúgú de Havestadt (1777). Este ejercicio, además, permite proyectar trabajos futuros con este corpus, ya sea en relación con las ideologías lingüísticas, sus paratextos o el análisis lingüístico propiamente tal. Esta afirmación se basa en que, pese a su relevancia, no tenemos noticias de que estos tratados se hubiesen estudiado antes desde el enfoque de las ideologías lingüísticas. Este fue uno de los motivos por los que abordamos este corpus y esperamos que este artículo pueda dar lugar a una discusión entre los especialistas de la lingüística misionera.

\section{Referencias bibliográficas}

Alvar, M. (1997). La gramática mapuche del padre Febres (1765). En Nebrija y estudios sobre la Edad de Oro (pp. 63-85). Madrid: Consejo Superior de Investigaciones Científicas, CSIC.

Anónimo [Valera, B.] (1586). Arte y vocabulario en la lengua del Perú llamada quichua, y en la lengua española. El más copioso y elegante que hasta ahora se ha impreso. Lima: Antonio Ricardo.

Araya, A. y Martínez, C. (2017). Nombrar el cuerpo en los vocabularios coloniales para el mapudungun de Chile (ss. XVII-XVIII). Atenea, 516(2), 13-32. https://scielo.conicyt.cl/pdf/atenea/ n516/0718-0462-atenea-516-00013.pdf

Bertonio, L. (2015). Arte y gramática muy copiosa de la lengua aymara. Primera Edición facsimilar. Puno: Universidad del Altiplano. (Trabajo original publicado en 1603).

Bouza Álvarez, F. (2018). Del escribano a la biblioteca. La civilización escrita europea en la alta Edad Moderna (siglos XV-XVII). Madrid: Akal. 
Breva-Claramonte, M. (2008). El marco doctrinal de la tradición lingüística europea y los primeros misioneros de la Colonia. Bulletin Hispanique, 110(1), 25-59, https://doi.org/10.4000/ bulletinhispanique.431

Bustamante, J. (2005). Español, lenguas generales y lenguas regionales: la definición de lengua imperial y de los niveles lingüísticos en el siglo XVI ante la experiencia americana. En P. Bárcenas de la Peña, S. Torallas, E. R. Luján, y M. A. Gallego (Eds.), Lenguas en contacto: el testimonio escrito (pp. 245-258). Madrid: Consejo Superior de Investigaciones Científicas, CSIC.

Calhoun, D. (2017). Reading paratexts in missionary linguistic works: An analysis of the preface to the Holy Ghost Fathers' (1855). Dictionnaire français-wolof et wolof-français. Language \& History, 60(1), 53-12. https://doi.org/10.1080/17597536.201 7.1297097

Calvo Pérez, J. (2013). Domingo de Santo Tomás o el extrañamiento de un precursor. En J. F. Forniés Casals y M. P. Numhauser (Eds.), Escrituras silenciadas: paisaje como historiografía (pp. 225-235). Alcalá de Henares: Universidad de Alcalá de Henares.

Cancino, N. (2017a). Los paratextos de artes y gramáticas misioneras americanas. Nueva Revista de Filología Hispánica, 65(2), 407-440, https://doi.org/10.24201/nrfh.v65i2.3101

Cancino, N. (2017b). Luis de Valdivia y la dimensión verbal de la conquista mapuche. En G. Rojo y C. Arcos (Coords. Grales.), S. Massmann (Coord. Vol.), Historia crítica de la literatura chilena, vol. I. La era colonial (pp. 381-394). Santiago de Chile: LOM ediciones.

Cancino, N. (2018). El español desde América: la visión de los misioneros coloniales. En M. L. Arnal Purroy, R. M. Castañer Martín, J. M. Enguita Utrilla, V. Lagüéns Gracia y M. A. Martín Zorraquino (Eds.), Actas del X Congreso Internacional de Historia de la Lengua Española, Zaragoza (pp. 1797-1810). Zaragoza: Institución Fernando el Católico/Excma. Diputación Provincial Zaragoza.

Cancino, N. (2020). El modelo latino en las primeras descripciones del mapudungun: herencia e innovación en el saber lingüístico misionero-colonial. Revista ALEA-Estudos Neolatinos, 22(1), 263-280, https://doi.org/10.1590/1517-106x/2020221263280 
Cisternas, C. (2017). Ideologías lingüísticas: hacia una aproximación interdisciplinaria a un concepto complejo. Lenguas y Literaturas Indoamericanas, 19(1), 101-117. http://revistas.ufro.cl/ ojs/index.php/indoamericana/article/view/930

Esparza Torres, M. A. (2003). Lingüistas en la frontera: sobre las motivaciones, argumentos e ideario de los misioneros lingüistas. Romanistik in Geschichte und Gegenwart, 9(1), 67-92.

Esparza Torres, M. A. (2015). On the linguistic ideas underlying the work of 16th-century Mesoamerican missionaries. Historiographia Linguistica. International Journal for the History of the Language Science, 42(2-3), 211-231. https://doi. org/10.1075/hl.42.2-3.01esp

Esparza Torres, M. A. (2016). Elogio de la lengua nativa y planteamiento metalingüística en las gramáticas misioneras: el ejemplo de Domingo de Santo Tomás. Revista de Investigación Lingüistica, 19, 15-33. Recuperado de https://revistas.um.es/ ril/article/view/283511

Esparza Torres, M. A. (2017). Las ideas lingüísticas en los orígenes de la lingüística misionera en Mesoamérica: enunciados, argumentos, imágenes y ejemplos. RILCE, Revista de Filología Hispánica, 33(1), 135-164. https://doi. org/10.15581/008.33.1.135-64

Esparza Torres, M. A. (2019). La lingüística misionera en Michoacán: relaciones textuales entre los prólogos de Alonso de Molina y Maturino Gilberti. En L. Alburquerque García, J. L. García Barrientos, A. Garrido Domínguez, A. Suárez Miramón (Coords.), Vir bonus dicendi: homenaje al profesor Miguel Ángel Garrido Gallardo (pp. 127-134). Madrid: Consejo Superior de Investigaciones Científicas, CSIC.

Febres, A. (1765). Arte de la lengua general del Reyno de Chile. Con un dialogo chileno-hispano muy curioso: a que se añade La Doctrina Christiana, esto es, Rezo, Catecismo, Coplas, Confesionario, y Pláticas; lo mas en Lengua Chilena y Castellana: $y$ por fin un vocabulario hispano-chileno, y un calepino Chileno-Hispano mas copioso. Lima: Calle de la Encarnación.

Flores Farfán, J. A. y Zwartjes, O. (2018). La "Protesta” (1723) del agustino Manuel Pérez, el primer tratado de teoría de la traducción en náhuatl. Estudios de Cultura Náhuatl, 55, 173-224. 
Garrett, P. (2010). Attitudes to language. Cambridge: Cambridge University Press.

Gómez Asencio, J. (2002). El prólogo como programa. A propósito de la GRAE de 1771. En M. T. Echenique y J. P. Sánchez Méndez (Coords.), Actas del $V$ Congreso Internacional de Historia de la Lengua Española, Valencia, (pp. 1201-1215). Madrid: Gredos.

Hanks, W. (2000). Indexicality. Journal of Linguistic Anthropology, 9(12), 124-126. https://doi.org/10.1525/jlin.1999.9.1-2.124

Havestadt, B. de. (1777). Chilidúgúsive res chilenses. Westphalium: Aschendorfus.

Hernández, A. (2013). Las lenguas mesoamericanas y la tradición gramatical grecolatina: encuentro y respuesta. En B. Arias, B. M. G. Juárez, y J. Nadal (Eds.), Mosaico de estudios coloniales. I Coloquio Internacional Lenguas y Culturas Coloniales 2008 (pp. 25-56). México, D.F.: Universidad Autónoma de México, UNAM.

Irvine, J. (1989). When talk isn't cheap: Language and political economy. American Ethnologist, 16(2), 248-267. https://doi. org/10.1525/ae.1989.16.2.02a00040

Kroskrity, P. (2004). Language ideologies. En A. Duranti (Ed.), A companion to linguistic anthropology (pp. 496-517). Oxford: Blackwell Publishing.

Kroskrity, P. (2010). Language ideologies: Evolving perspectives. En J. Jaspers, J. Östman, \& J. Verschueren (Eds.), Society and language use (pp. 192-211). Amsterdam: John Benjamins, 2010. Recuperado de https://www.researchgate.net/publication/285809637_Language_ideologies_Evolving_perspectives Martínez Baracs, R. (1997). El Vocabulario en lengua de Mechuacan (1559) de Fray Maturino Gilberti como fuente de información histórica". En C. Paredes (Ed.), Lengua y etnohistoria purépecha. Homenaje a B. Warren (pp. 67-162). Morelia: IIH-Universidad Michoacana de S. Nicolás de HidalgoCIESAS.

Moreno, R. (2009). La organización eclesiástica chilena en tiempos coloniales, siglos XVI-XVIII. En M. Sánchez Gaete (Dir.), Historia de la Iglesia en Chile, I. En los caminos de la conquista espiritual (pp. 85-120). Santiago de Chile: Editorial Universitaria. 
Muñoz, M. (1994). Elogio y defensa de la lengua española en Bernardo de Aldrete. En R. Escavy, J. M. Hernández Terrés, y A. Roldán (Eds.), Actas del Congreso Internacional de Historiografía Lingüistica "Nebrija V Centenario 1492-1992" (pp. 451-475.). Murcia: Universidad de Murcia.

Narvaja, E. y Valle, J. del (2010). Las representaciones ideológicas del lenguaje. Discurso glotopolítico y panhispanismo. Spanish in Context, 7(1), 1-24. https://doi.org/10.1075/sic.7.1.01nar

Olate Vinet, A., Cisternas, C., Wittig, F., y Flores, J. (2017). Los misioneros capuchinos bávaros y sus ideologías lingüísticas sobre la lengua mapuche. Nueva Revista del Pacífico, 67, 130-156. https://doi.org/10.4067/s0719-51762017000200130

Oesterreicher, W. (2019). La gramática colonial en América como forma histórica del saber lingüístico. En R. Cerrón-Palomino, A. Ezcurra Rivero, y O. Zwartjes (Eds.), Lingüistica misionera. Aspectos lingüísticos, discursivos, filológicos y pedagógicos (pp. 409-439). Lima: Pontificia Universidad Católica del Perú, PUCP.

Ridruejo. E. (2007). El Arte de la lengua de Chile de Luis de Valdivia. Madrid: Agencia Española de Cooperación Internacional para el Desarrollo, AECID.

Rojas, D. (2013). Actitudes e ideologías de hispanohablantes en torno a las lenguas indígenas en el Chile del siglo XIX. Lenguas Modernas, 42, 85-98. http://repositorio.uchile.cl/handle/2250/123087

Rosa, M. C. (1997). Línguas bárbaras e peregrinas do Novo Mundo segundo os gramáticos jesuítas: Uma concepção de universalidade no estudo de línguas estrangeiras. Revista de Estudos da Linguagem 6(2), 97-148. https://doi.org/10.17851/22372083.6.2.97-149

Rumsey, A. (1990). Wording, meaning, and linguistic ideology. American Anthropologist 92(2), 346-361. https://doi.org/10.1525/ aa.1990.92.2.02a00060

Santo Tomás, D. (1560). Arte de la lengua general del Perú, llamada Quichua. Valladolid.

Silverstein, M. (1979). Language structure and linguistic ideology. En P. Clyne, W. Hanks, \& C. Hofbauer (Eds.), The elements (pp. 193-248). Chicago: Chicago Linguistics Society. 
Spolsky, B. (2004). Language policy. Cambridge: Cambridge University Press.

Swiggers, P. (2009). La historiografía de la lingüística: apuntes y reflexiones. Revista Argentina de Historiografía Lingüistica, l(1), 67-76. https://rahl.com.ar/index.php/rahl/article/ view/6/18

Valdivia, L. de. (1606). Arte y gramatica general de la lengva que corre en todo el Reyno de Chile, con vn Vocabulario y Confessonario. Lima: Francisco del Canto.

Valle, J. del y Meirinho-Guede, V. (2015). Ideologías lingüísticas. En J. Gutiérrez (Coord.), Enciclopedia de lingüistica hispana, vol. 2 (pp. 622-631). New York: Routledge.

Viereck Salinas, R. (2017). Introducción. En G. Rojo y C. Arcos (Coords. Grales.), S. Massmann (Coord. Vol.), Historia crítica de la literatura chilena, volumen I. La era colonial (pp. 367-374). Santiago: LOM ediciones.

Woolard, K. (1998). Introduction: language ideology as a field of inquiry. En B. Schieffelin, K. Woolard y P. Kroskrity (Eds.), Language ideology. Practice and theory (pp. 3-47). Oxford: Oxford University Press.

Zimmermann, K. (2006). Las gramáticas y los vocabularios misioneros: entre la conquista y la construcción transcultural de la lengua del otro. En P. Máynez (Ed.), Actas del V Encuentro de Lingüistica de la Facultad de Estudios Superiores Acatlán (pp. 319-356). México, D.F.: Universidad Autónoma de México, UNAM.

Zwartjes, O. (1998). La estructura de la palabra según las primeras gramáticas de lenguas mesoamericanas y la tradición grecolatina. En D. Jorques y J. Calvo (Eds.), Estudios de lengua y cultura amerindias II: lenguas, literaturas y medios (pp. 99121). Valencia: Universidad de Valencia. 